\title{
A Case for Government-Industry Partnerships
}

\author{
Robert M. Purgert \\ Thompson Aluminum Casting Co., Inc.
}

Permission is hereby granted for a copyright release fee of $\$ 300$ per paper. An invoice will follow under separate cover. Please be sure to include the following credit statement with these papers:

" Society of Automotive Engineers, Inc. The following papers are published on this web-site with permission from the Society of Automotive Engineers, Inc. As a user of this web-site, you are permitted to view these papers on-line, download the PDF file and to print a copy at no cost for your use only. Dowloaded PDF files and printouts of SAE papers contained on this web-site may not be copied or distributed to others or for the use of others." 
The appearance of this ISSN code at the bottom of this page indicates SAE's consent that copies of the paper may be made for personal or internal use of specific clients. This consent is given on the condition, however, that the copier pay a $\$ 7.00$ per article copy fee through the Copyright Clearance Center, Inc. Operations Center, 222 Rosewood Drive, Danvers, MA 01923 for copying beyond that permitted by Sections 107 or 108 of the U.S. Copyright Law. This consent does not extend to other kinds of copying such as copying for general distribution, for advertising or promotional purposes, for creating new collective works, or for resale.

SAE routinely stocks printed papers for a period of three years following date of publication. Direct your orders to SAE Customer Sales and Satisfaction Department.

Quantity reprint rates can be obtained from the Customer Sales and Satisfaction Department.

To request permission to reprint a technical paper or permission to use copyrighted SAE publications in other works, contact the SAE Publications Group.

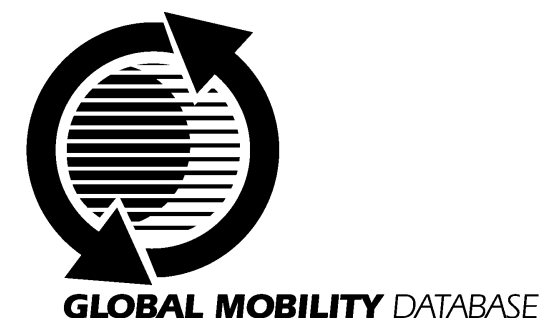

All SAE papers, standards, and selected books are abstracted and indexed in the Global Mobility Database

No part of this publication may be reproduced in any form, in an electronic retrieval system or otherwise, without the prior written permission of the publisher.

\section{ISSN 0148-7191}

Copyright 1999 Society of Automotive Engineers, Inc.

Positions and opinions advanced in this paper are those of the author(s) and not necessarily those of SAE. The author is solely responsible for the content of the paper. A process is available by which discussions will be printed with the paper if it is published in SAE Transactions. For permission to publish this paper in full or in part, contact the SAE Publications Group.

Persons wishing to submit papers to be considered for presentation or publication through SAE should send the manuscript or a 300 word abstract of a proposed manuscript to: Secretary, Engineering Meetings Board, SAE.

\section{Printed in USA}




\title{
A Case for Government-Industry Partnerships
}

\author{
Robert M. Purgert \\ Thompson Aluminum Casting Co., Inc.
}

Copyright (c) 1999 Society of Automotive Engineers, Inc.

\begin{abstract}
Government-industry partnerships are necessary for small businesses to successfully launch new and innovative ideas into the market place. Small businesses, the cornerstone for economic job creation, expansion and retention, is hampered with the need to fund new and innovative technologies from profits which generally occur in a cyclic manner. This cyclic funding leads to ramp ups and development during profitable years, and delays and abeyance during years of downturn. Government-industry partnerships directly addresses this problem by offering funding assistance in the form of resources eliminating the "peaks and valleys" of development. This paper will detail a case study of this type of assistance.
\end{abstract}

\section{INTRODUCTION}

Thompson Aluminum Casting Company, Inc. (TAC) developed a new squeeze casting process called metal compression forming (MCF), in which metal is allowed to solidify under pressure in order to close porosity and form a sound part. The MCF process applies pressure on the entire mold face, thereby directing pressure on all regions of the casting and producing a uniformly sound part.

This "direct" squeeze casting method results in a very fine microstructure and the elimination of macro-porosity in the component. These enhancements result in a near net shape component with mechanical properties capable of competing with forgings. An added benefit is that the properties are isotropic whereas forgings are anisotropic or directional.

A prototype machine producing test bars was constructed, however an actual demonstration project where a component might be produced was needed to fully demonstrate the capability of the process needed for commercialization. This demonstration project was achieved by the use of a cooperative research \& development agreement (CRADA) with the U.S. Department of Energy, without which, full-scale commercialization would have been delayed.

\section{COOPERATIVE RESEARCH AND DEVELOPMENT AGREEMENTS-A VIABLE SOLUTION}

THE NEED TO DEMONSTRATE - Though a series of test bars were produced using a prototype MCF machine, one of the stumbling blocks for fully commercializing the process was the often heard comment "have you made any parts with it". This reluctance by design engineers, particularly in the automotive industry, to use a technology that was never before attempted, led to the formation of a cooperative research and development agreement between Thompson Aluminum Casting Company (a small Cleveland area foundry) and the U.S. Department of Energy.

It is very important to note that the CRADA in and of itself was instrumental in gaining the acceptance of an automotive company to participate on the demonstration project. A small business armed only with an "idea" that a new technology might expand the use of light weight materials to assist automotive companies in achieving CAFE standards was a difficult enticement to auto companies who sort through a myriad of new "ideas" for making cars every day.

Recognizing this drawback, Thompson Aluminum Casting Company approached Dr. Sidney Diamond at the U.S. Department of Energy to determine whether any assistance might be provided to aid in demonstrating the process to industry. Dr. Diamond reviewed the proposed project requirements and determined that the most optimum means for addressing the needs was through a CRADA mechanism.

The use of the CRADA was instrumental in gaining the acceptance of Delphi Chassis for participating on the project. Armed with the capabilities and assistance afforded by U.S. Department of Energy and Oak Ridge National Laboratory to support needed testing and modeling, Delphi agreed to become a participant on a CRADA and ultimately qualified the component produced under the CRADA. 
The Challenge - The initial CRADA concept called for identification of a component to be produced under the program to demonstrate process capabilities. Components being considered were those that were in production so that a baseline would be available to formulate comparisons to traditional manufacturing techniques.

The CRADA was signed in late 1994. At the initial "kickoff" meeting, Delphi suggested that the team consider the possibility of producing an aluminum MCF motor-mount casting. These castings could be simultaneously prototype tested along with an aluminum forging currently under development. This was an ideal candidate part as the motor mount was being designed in a light-weight material to substitute for a cast iron component, however the added costs of forging needed to achieve mechanical properties might make it a less desirable substitution.

The team determined that the opportunity to demonstrate that an MCF-produced component was capable of achieving the needed mechanical properties while also substantially reducing the unit costs would be a significant benefit for demonstrating the commercial potential of the process. This challenge, however, required that parts be available for prototype testing within 4 months.

"Mini-Manhattan Project" - A follow-up meeting was held the next day, December 1, 1994, at Oak Ridge National Laboratory to discuss the Delphi "challenge". It was decided at that meeting to accept the accelerated delivery schedule to produce an aluminum A356 MCF component that would be a suitable replacement for an aluminum forging made from 6061 alloy.

The pros and cons discussed at the meeting outlined the advantages of accepting the accelerated delivery schedule as being an opportunity to demonstrate the technology on a "live fire" part. It also clearly pointed out the necessity for the partnership as the analytical and modeling capabilities afforded by ORNL would be absolutely necessary and the only means for meeting the accelerated delivery date for prototype testing components.

Recognizing the unqualified need for the close cooperation and tandem support, Dr. Diamond, the DOE Program Manager, required and obtained a formal commitment from each of the CRADA participants that they would do whatever was needed to meet the delivery requirement. The project was then deemed the "miniManhattan" project and the challenge was accepted.

The project team identified areas where the relative expertise of the team members could be most advantageously applied. Particular emphasis on computer modeling, die design, process parameters (die temperatures, melt temperatures, flow rates, squeeze pressure, cycle times, etc.) were assigned to ORNL as the resources to perform such activities were only available at the ORNL site. TAC was assigned to run the parts on their MCF system and to perform the trial and error to perfecting the process. Delphi agreed to perform qualification testing of the component.

Dies were designed, modeled, fabricated, modified, mounted on the MCF machine and debugged leading to the successful production of a component for prototype testing within the 4-month time frame.

The subsequent result was that the components were produced on time and successfully submitted for qualification testing to the ultimate automotive user, Delphi Chassis, who qualified the process for use.

The Need for Partnerships - The TAC/DOE CRADA demonstrated four major needs and benefits of government/industry partnerships, particularly those that are beneficial for small businesses.

Legitimacy-First and foremost, the addition of the Department of Energy and Oak Ridge National Laboratory to the project team demonstrated that the project had sufficient merit to warrant attention of experts in the field of material science. This recognition was instrumental in gaining acceptance by the user industry of the technology's potential, negating the skepticism very often attached to new technologies offered by small businesses as being merely funding exercises to keep certain "pet ideas" alive.

Resources - The resources made available to small businesses via the national laboratories cannot be duplicated by most small firms. Additionally, the skilled, trained technicians to operate the equipment are "onhand" at the national laboratories adding the benefit that would be cost prohibitive to all but a very few large corporate entities. Finally, the resources applied to the effort are those that are truly needed, not just those that are available which are sometimes "form fit" to the project.

Marketability - The result of the assistance offered via a government/industry partnership leads to increased marketability for the technology. Lead times are significantly lessened from development to commercialization, a key attribute for any successful commercialization. Also, the validation and resources brought to the project by the government participant provide the mechanism for penetrating the "gate keepers" at most user industries permitting access to key design engineers.

Validation - The ultimate benefit for the partnership is the independent validation of the project afforded by test results obtained at the national laboratories. The credibility and reputation of the national laboratories for excellence and the integrity of data produced by them permits all reviewers to confidently use the information generated as a basis for decision making. 


\section{CONCLUSION}

Government-industry partnerships are one of the most successful means for small businesses to introduce new technologies into the market place quickly. Resources and credibility afforded by government partnerships move small business' new and innovative technologies from the drawing board to the decision makers much more readily than traditional means because of the added credibility bolstered by resources available to few small businesses.

\section{ACKNOWLEDGMENTS}

The Thompson Aluminum Casting Company would like to acknowledge the drive and dedication provided by Dr. Sidney Diamond, U.S. Department of Energy, which was instrumental for the successful completion of the effort.

\section{CONTACT}

For more information on the MCF process or the U.S. DOE/TAC CRADA, please contact:

Robert M. Purgert

Thompson Aluminum Casting Company, Inc.

P.O. Box 25441

Cleveland, $\mathrm{OH} 44125$

Purgert@msn.com

\section{DEFINITIONS, ACRONYMS, ABBREVIATIONS}

CRADA: Cooperative research \& development agreement between government and industry.

MCF: Metal compression forming, a new and advanced squeeze casting process.

TAC: Thompson Aluminum Casting Company, Inc. 